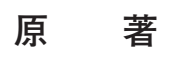

\title{
当院における破裂脳動脈瘤の大きさによる臨床的特徵・予後の検討
}

\author{
山岡 寛人, 菅原 貴志, 稲次 基希, 田中 洋次 \\ 吉野 義一, 成相 直, 根本 繁, 前原 健寿
}

\section{Clinical Analysis of the Size of Ruptured Aneurysms}

\author{
Hiroto Yamaoka, M.D., Takashi Sugawara, M.D., Ph.D., Motoki InaJI, M.D., Ph.D., \\ Youji Tanaka, M.D., Ph.D., Kazuyoshi Yoshino, M.D., Ph.D., Tadashi NariaI, M.D., Ph.D., \\ Shigeru Nemoto, M.D., Ph.D., and Taketoshi Maehara, M.D., Ph.D. \\ Department of Neurosurgery, Tokyo Medical and Dental University, Tokyo, Japan
}

\begin{abstract}
Summary: Introduction: Both the size and location of unruptured intracranial aneurysms have been frequently researched in the last decades. However, little is known about ruptured intracranial aneurysms (RIAs). In this study, we thus aimed to verify whether the size of RIAs affects prognosis and clinical features.

Material and Methods: A total of 185 patients with RIAs, who were treated in our hospital between September 2008 and December 2015, were analyzed in the present study. Specifically, the relationship between the size of the RIA and the operative outcome (mRS) was investigated. Furthermore, the incidence of complications associated with operative procedures depending on the aneurysmal size was also evaluated. Finally, we analyzed the relationship between the size of RIAs and their location, patients' sex and age, surgical procedure (clip or coil), severity on admission (GCS), and frequency of intracranial hemorrhage (ICH), intraventricular hemorrhage (IVH), and cerebral vasospasm.

Results: The average maximum diameter of RIAs was significantly larger in males than females (6.7 and $5.6 \mathrm{~mm}$, respectively; $\mathrm{p}=0.012$ ), in patients with ICH than in those without it (6.6 and $5.6 \mathrm{~mm}$, respectively; $\mathrm{p}=0.042$ ), and in the poor outcome group ( $\mathrm{mRS}=3-6)$ than in the good outcome one ( $\mathrm{mRS}=$ $0-2)$ (6.65 and $5.5 \mathrm{~mm}$, respectively; $p=0.003)$. Furthermore, MCA RIAs were significantly larger than RIAs located in the posterior circulation ( 6.6 and $4.2 \mathrm{~mm}$, respectively; $\mathrm{p}<0.05$ ). Subsequently, the 185 patients were divided into two groups, namely the good and poor outcome groups, to analyze the prognostic factors. Our results indicated the following to be independent poor prognostic factors: advanced age (55.3 vs 28.6\%; OR: 0.269; CI: 95\%; 0.127-0.569), IVH (76.7 vs 35.5\%; OR: 0.24; CI: 95\%; 0.0837-0.688), GCS $\leqq 13$ ( 66.7 vs $18.9 \%$; OR: 0.226 ; CI: $95 \%$; $0.101-0.508$ ), and RIAs of size $\geqq 6 \mathrm{~mm}$ (50.5 vs $32.6 \%$; OR: 0.468 ; CI: $95 \% ; 0.222-0.99, \mathrm{p}=0.047)$. With regards to the incidence of complications associated with operative procedures depending on the aneurysmal size, the following factors were not significantly different between the two groups: $(<6 \mathrm{~mm}$ and $\geqq 6 \mathrm{~mm}$ : intraoperative aneurysmal rupture (9.3 vs $11.1 \% ; \mathrm{p}=0.872$ ), infarctions (9.3 vs $9.1 \% ; \mathrm{p}=0.837$ ), and contusions ( 1.2 vs $6.1 \% ; \mathrm{p}=0.175$ ).

Finally, the 185 patients were additionally divided into two further groups based on their aneurysmal size (either $\geqq 6$ or $\leqq 6 \mathrm{~mm}$ ) to compare their clinical features. A univariate analysis suggested the RIAs located on the MCA to be likely to grow larger than $6 \mathrm{~mm}$ compared to those placed elsewhere. In contrast, multivariate analysis indicated the male parameter to be the only independent factor to be correlated with an aneurysmal size $\geqq 6 \mathrm{~mm}$.
\end{abstract}

Conclusion: RIAs of a size $\geqq 6 \mathrm{~mm}$ appear more frequently in males and result in poor outcome.

東京医科歯科大学 脳神経外科(受稿日 2018. 2. 7) (脱稿日 2018.9.10) 〔連絡先： ₹ 113-8519 東京都文京区湯島 1-5-45 東京医科歯科大学 脳神経外科 菅原貴志] [Address correspondence: Takashi Sugawara, M.D., Ph.D., Department of Neurosurgery, Tokyo Medical and Dental University, 1-5-45 Yushima, Bunkyo-ku, Tokyo 113-8519, Japan]

\author{
Key words: \\ - aneurysmal size \\ $\cdot$ prognostic factor \\ $\cdot \mathrm{SAH}$
}

Surg Cereb Stroke

(Jpn) 48: 25-29, 2020 


\section{はじめに}

動脈瘤の大きさは, 未破裂脳動脈瘤の破裂因子とされて いる ${ }^{8) 13)}$. 本邦の未破裂脳動脈瘤における大規模観察研究 の報告では，脳動脈瘤のサイズ，部位，ブレブを伴う形状 が破裂に関与する因子とされており ${ }^{12)}, 2014$ 年に報告さ れた未破裂脳動脈瘤の破裂を予測する PHASES scoreに よれば, 70 歳以下で前方循環に生じた $10 \mathrm{~mm}$ 以下の脳動 脈瘤が破裂する危険性は $1 \%$ 以下であり，10 mm 以上で破 裂率が有意に高くなっている 脈瘤は前方循環で，サイズが大きく破裂頻度も高いという 報告はあるものの ${ }^{8)}$, 破裂脳動脈瘤のサイズと予後や臨床 的特徵を関連づけた報告は少ない1111)14)。今回われわれ は，当院で治療した破裂脳動脈瘤患者の予後に関してサイ ズを含めた危険因子を検討し，また破裂脳動脈瘤サイズと 臨床的特徵に関しても検討を行った。

\section{対象・方法}

この研究は院内倫理審査委員会により認可されている (承認番号 1543)。2008 年 9 月から 2015 年 12 月の間に当 院で開頭ネッククリッピング術または血管内コイル塞栓術 を行った破裂脳動脈瘤患者連続 215 例中, 破裂部位が同定 できなかった 1 例と解離性脳動脈瘤 29 例を除いた 185 例 を対象とした。

動脈瘤の最大径は, 脳血管撮影 (digital subtraction angiography：DSA)または CT angiography(CTAG)を用いて 計測した。

年齢 (60 歳未満, 60 歳以上), 性別, 部位(内頝動脈系 $[\mathrm{IC}]$, 前大脳動脈系〔 $\mathrm{AC}]$, 中大脳動脈〔 $\mathrm{MC}$ ，後方循環 $[\mathrm{P}])$, 脳内出血 (ICH)の有無・脳室内出血(IVH)の有無, 重症度 (Glasgow Coma Scale: GCS), 術式 (clip, coil), 脳血管攣縮の有無, 予後 (良好群 : modified Rankin Scale 〔mRS $]=0 ， 1 ， 2$, 不良群 $: \mathrm{mRS}=3 ， 4 ， 5 ， 6)$ のそれぞ れにおいて, 破裂脳動脈瘤の平均最大径を比較した。続い て，予後良好群 $(\mathrm{mRS}=0-2)$ と予後不良群 $(\mathrm{mRS}=3-6)$ の 2 群に分け, 年歯 (60 歳未満, 60 歳以上), 性別, 部位 (IC, AC, MC, P), ICH の有無・IVH の有無, modified Fisher $\operatorname{group}(1,2$ or 3$)$, 無症候性脳血管攣縮の有無, 症候性脳 血管攣縮の有無, 動脈瘤サイズ $(<6,6 \leqq)$ に関して予後不 良因子を検討した。また，動脈瘤の大きさによる，術中破 裂，手術操作による脳梗塞・脳挫傷の発生頻度に関して比 較検討した。ささに, 破裂脳動脈瘤の最大径 $6 \mathrm{~mm}$ 以上と $6 \mathrm{~mm}$ 未満の 2 群に分け, 年齢 (60 歳未満, 60 歳以上), 性 別, 部位 (IC, AC, MC, P), ICH の有無・IVH の有無, modified Fisher group (1, 2 or 3$)$, 重症度 $(\mathrm{GCS}<13$ or 14 , 15)に関して比較検討した。血腫量の評価として, Fisher
Table 1 Clinical features and average maximum diameter of RIAs

\begin{tabular}{|c|c|c|c|}
\hline & & $\begin{array}{c}\text { Size of } \\
\text { RIAs }(\mathrm{mm})\end{array}$ & $p$ value \\
\hline \multirow[t]{2}{*}{ Age (years) } & $<60$ & 6.28 & 0.105 \\
\hline & $60 \leqq$ & 5.8 & \\
\hline \multirow[t]{2}{*}{ Sex } & M & 6.7 & 0.012 \\
\hline & $\mathrm{F}$ & 5.6 & \\
\hline \multirow[t]{5}{*}{ Location } & IC & 6 & 0.018 \\
\hline & $A C$ & 5.7 & \\
\hline & $\mathrm{MC}$ & 6.6 & \\
\hline & $P$ & 4.2 & \\
\hline & & & $M C$ vs $P<0.05$ \\
\hline \multirow[t]{2}{*}{$\mathrm{ICH}$} & With & 6.6 & 0.042 \\
\hline & Without & 5.6 & \\
\hline \multirow[t]{2}{*}{ IVH } & With & 6.7 & 0.221 \\
\hline & Without & 7 & \\
\hline \multirow[t]{2}{*}{ Procedure } & Clip & 6 & 0.622 \\
\hline & Coil & 5.9 & \\
\hline \multirow[t]{2}{*}{ Asymptomatic VS } & With & 6 & 0.444 \\
\hline & Without & 6 & \\
\hline \multirow[t]{2}{*}{ Symptomatic VS } & With & 6 & 0.5 \\
\hline & Without & 6 & \\
\hline \multirow[t]{2}{*}{$\mathrm{mRS}$} & $0,1,2$ & 5.5 & 0.003 \\
\hline & $3,4,5,6$ & 6.65 & \\
\hline
\end{tabular}

RIA: ruptured intracranial aneurysm, M: male, F: female, IC: internal carotid artery, AC: anterior cerebral artery, MC: middle cerebral artery, $\mathrm{P}$ : posterior cerebral artery, $\mathrm{ICH}$ : intracerebral hemorrhage, IVH: Intraventricular hemorrhage, VS: vasospasm, mRS: modified Rankin Scale

の分類 ${ }^{3)}$ を部修正し, group 4 の症例の脳内血腫を無視 した純粋なくも膜下血腫の量のみで group 1-3 へ再分類し た。これにより，純粋なくも膜下血腫の量に対応した grade として扱うことができ，ここでは modified Fisher grade と定義する.

統計には 2 群間の比較に t-test， $\chi^{2}$ test，多群間の比較に one way ANOVA, 多要因の解析に multiple logistic regression analysis 用いた. ソフトウェアはSigmaStat 3.5 を 使用した。有意水準は $5 \%$ とした。

\section{結果}

まず，破裂脳動脈瘤の最大径の平均を各項目で比較した 結果を Table 1 に示す. 破裂脳動脈瘤の最大経は, 男性 (6.7 vs $5.6 \mathrm{~mm}, \mathrm{p}=0.012$ ), ICH 合併群 (6.6 vs $5.6 \mathrm{~mm}$, p $=0.042$ ), 予後不良群 (6.65 vs $5.5 \mathrm{~mm}, \mathrm{p}=0.003)$ で有意に 大きかった，また，中大脳動脈に発生した動脈瘤は，後方 循環に発生した動脈瘤と比較して有意に大きかった(6.6 vs $4.2 \mathrm{~mm}, \mathrm{p}<0.05)$ 。 その他, 年齢, IVH の有無, 術式, 無 
Table 2 Comparison of the clinical features between patients with different mRS values (i.e., $\leqq 2$ or $\geqq 3$ )

\begin{tabular}{|c|c|c|c|c|c|c|c|}
\hline & & \multicolumn{2}{|c|}{$\mathrm{mRS}$} & \multirow{2}{*}{$\begin{array}{c}\text { Univariate } \\
\text { analysis } \\
\text { ( } p \text { value) }\end{array}$} & \multicolumn{3}{|c|}{ Multiple logistic regression analysis } \\
\hline & & $\begin{array}{c}0,1,2 \\
n=107\end{array}$ & $\begin{array}{c}3,4,5,6 \\
n=78\end{array}$ & & Odds ratio & $95 \% \mathrm{Cl}$ & $p$ value \\
\hline \multirow[t]{2}{*}{ Age (years) } & $<60$ & $60.7 \%$ & $33.3 \%$ & $<0.001$ & 0.269 & $0.127-0.569$ & $<0.001$ \\
\hline & $60 \leqq$ & $39.3 \%$ & $66.7 \%$ & & & & \\
\hline \multirow[t]{2}{*}{ Sex } & M & $43.0 \%$ & $35.9 \%$ & 0.412 & & & \\
\hline & $\mathrm{F}$ & $57.0 \%$ & $64.1 \%$ & & & & \\
\hline \multirow[t]{5}{*}{ Location } & IC & $34.6 \%$ & $20.5 \%$ & 0.005 & & & \\
\hline & $A C$ & $42.1 \%$ & $32.1 \%$ & & & & \\
\hline & MC & $18.7 \%$ & $33.3 \%$ & vs others 0.035 & 0.514 & $0.224-1.184$ & 0.118 \\
\hline & $P$ & $4.67 \%$ & $14.1 \%$ & & & & \\
\hline & $I C+A C+P$ & $81.3 \%$ & $66.7 \%$ & & & & \\
\hline \multirow[t]{2}{*}{$\mathrm{ICH}$} & With & $15.9 \%$ & $39.7 \%$ & $<0.001$ & 0.592 & $0.238-1.471$ & 0.259 \\
\hline & Without & $84.1 \%$ & $60.3 \%$ & & & & \\
\hline \multirow[t]{2}{*}{$\mathrm{IVH}$} & With & $6.54 \%$ & $29.5 \%$ & $<0.001$ & 0.24 & $0.0837-0.688$ & 0.008 \\
\hline & Without & $93.5 \%$ & $70.5 \%$ & & & & \\
\hline \multirow[t]{2}{*}{ mFisher } & 3 & $76.6 \%$ & $85.9 \%$ & 0.167 & 0.623 & $0.225-1.72$ & 0.361 \\
\hline & 1,2 & $23.4 \%$ & $14.1 \%$ & & & & \\
\hline \multirow[t]{2}{*}{ GCS } & $\leqq 13$ & $28.0 \%$ & $76.9 \%$ & $<0.001$ & 0.226 & $0.101-0.508$ & $<0.001$ \\
\hline & 14,15 & $72.0 \%$ & $23.1 \%$ & & & & \\
\hline \multirow[t]{2}{*}{ Asymptomatic VS } & With & $34.6 \%$ & $27.0 \%$ & 0.343 & & & \\
\hline & Without & $65.4 \%$ & $73.1 \%$ & & & & \\
\hline \multirow[t]{2}{*}{ Symptomatic VS } & With & $11.2 \%$ & $7.70 \%$ & 0.584 & & & \\
\hline & Without & $88.8 \%$ & $92.3 \%$ & & & & \\
\hline \multirow[t]{2}{*}{ Size of RIAs } & $<6$ & $54.2 \%$ & $35.9 \%$ & 0.021 & 0.468 & $0.222-0.99$ & 0.047 \\
\hline & $6 \leqq$ & $45.8 \%$ & $64.1 \%$ & & & & \\
\hline
\end{tabular}

mRS: modified Rankin Scale, M: male, F: female, IC: internal carotid artery, AC: anterior cerebral artery, MC: middle cerebral artery, P: posterior cerebral artery, ICH: intracerebral hemorrhage, IVH: intraventricular hemorrhage, VS: vasospasm, mFisher: modified Fisher, GCS: Glasgow Coma Scale

症候性脳血管攣縮の有無, 症候性脳血管攣縮の有無では動 脈瘤の最大径に有意差を認めなかった.

予後良好群と予後不良群において，それぞれの項目に対 して単変量解析および多変量解析を行った結果を Table 2 に示す．単変量解析では 60 歳以上 $(55.3 \%$ vs $28.6 \%$, p $<$ $0.001), \operatorname{MC}(56.5 \%$ vs $37.4 \%, \mathrm{p}=0.035)$, $\mathrm{ICH}(64.6 \%$ vs $34.3 \%, \mathrm{p}<0.001), \operatorname{IVH}(76.7 \%$ vs $35.5 \%, \mathrm{p}<0.001)$, $\mathrm{GCS} \leqq 13(66.7 \%$ vs $18.9 \%, \mathrm{p}<0.001)$ ，破裂脳動脈瘤サイ ズ $\geqq 6 \mathrm{~mm}(50.5 \%$ vs $32.6 \%, \mathrm{p}=0.021)$ で予後不良例が有意 に多く, 多変量解析では 60 歳以上 $(55.3 \%$ vs $28.6 \%$ : OR $0.269 ; 95 \%$ CI $0.127-0.569)$, IVH $(76.7 \%$ vs $35.5 \%$ : OR $0.24 ; 95 \%$ CI $0.0837-0.688)$, GCS $\leqq 13(66.7 \%$ vs $18.9 \%$ : OR 0.226 ; $95 \%$ CI 0.101-0.508), 破裂脳動脈瘤サイズミ $6 \mathrm{~mm}(50.5 \%$ vs $32.6 \%$ : OR $0.468 ; 95 \%$ CI $0.222-0.99$, p $=0.047)$ が独立予後不良因子であった. 術中破裂や手術操 作による脳梗塞・脳挫傷の発生頻度を $6 \mathrm{~mm}$ 以上と $6 \mathrm{~mm}$ 未満の 2 群に分けて単変量解析した結果を Table 3 に示
Table 3 Comparison of the incidence of complications associated with operative procedures

\begin{tabular}{cccc}
\hline & \multicolumn{2}{c}{ Size of RIAs } & Univariate \\
& $\begin{array}{c}<6 \mathrm{~mm} \\
\mathrm{n}=86\end{array}$ & $\begin{array}{c}\mathrm{n}=99 \\
\text { analysis } \\
\text { ( } \mathrm{p} \text { value) }\end{array}$ \\
\hline $\begin{array}{c}\text { Intraoperative } \\
\text { aneurysmal rupture } \\
\text { Infarction }\end{array}$ & $9.3 \%$ & $11.1 \%$ & 0.872 \\
Contusion & $9.3 \%$ & $9.1 \%$ & 0.837 \\
\hline
\end{tabular}

RIA: ruptured intracranial aneurysm

す。術中破裂 (9.3\% vs $11.1 \% \mathrm{p}=0.872)$ ，手術操作による 脳梗塞 $(9.3 \%$ vs $9.1 \%$ p =0.837), 手術操作による脳挫傷 (1.2\% vs $6.1 \% \mathrm{p}=0.175)$ のいずれも発生率に有意差を認め なかった.

臨床的特徵を $6 \mathrm{~mm}$ 以上と $6 \mathrm{~mm}$ 未満の 2 群に分けて単 変量解析および多変量解析した結果を Table 4 に示す. $6 \mathrm{~mm}$ 以上の破裂脳動脈瘤は発生部位に有意差を認め $(\mathrm{p}=$ 
Table 4 Comparison of clinical features between RIAs different in size $(<6$ or $\geqq 6 \mathrm{~mm})$

\begin{tabular}{|c|c|c|c|c|c|c|c|}
\hline & & \multicolumn{2}{|c|}{ Size of RIAs } & \multirow{2}{*}{$\begin{array}{c}\text { Univariate } \\
\text { analysis } \\
\text { ( } p \text { value) }\end{array}$} & \multicolumn{3}{|c|}{ Multiple logistic regression analysis } \\
\hline & & $\begin{array}{c}<6 \mathrm{~mm} \\
\mathrm{n}=86\end{array}$ & $\begin{array}{c}\geqq 6 \mathrm{~mm} \\
\mathrm{n}=99\end{array}$ & & Odds Ratio & $95 \% \mathrm{Cl}$ & p Value \\
\hline \multirow[t]{2}{*}{ Age (years) } & $<60$ & $45.3 \%$ & $52.5 \%$ & 0.409 & & & \\
\hline & $60 \leqq$ & $54.7 \%$ & $47.5 \%$ & & & & \\
\hline \multirow[t]{2}{*}{ Sex } & M & $33.7 \%$ & $45.5 \%$ & 0.14 & 1.954 & $1.04-3.671$ & 0.037 \\
\hline & $\mathrm{F}$ & $66.3 \%$ & $54.5 \%$ & & & & \\
\hline \multirow[t]{5}{*}{ Location } & IC & $26.7 \%$ & $30.3 \%$ & 0.021 & & & \\
\hline & $A C$ & $41.9 \%$ & $34.3 \%$ & & & & \\
\hline & MC & $17.4 \%$ & $31.3 \%$ & vs others 0.045 & 1.877 & $0.899-3.921$ & 0.094 \\
\hline & $P$ & $14.0 \%$ & $4.04 \%$ & & & & \\
\hline & $I C+A C+P$ & $82.6 \%$ & $68.7 \%$ & & & & \\
\hline \multirow[t]{2}{*}{$\mathrm{ICH}$} & With & $18.6 \%$ & $32.3 \%$ & 0.051 & 2.038 & $0.917-4.529$ & 0.081 \\
\hline & Without & $81.4 \%$ & $67.7 \%$ & & & & \\
\hline \multirow[t]{2}{*}{$\mathrm{IVH}$} & With & $16.3 \%$ & $16.2 \%$ & 0.858 & & & \\
\hline & Without & $83.7 \%$ & $83.8 \%$ & & & & \\
\hline \multirow[t]{2}{*}{ mFisher } & 3 & $75.6 \%$ & $84.8 \%$ & 0.161 & 2.158 & $0.97-4.8$ & 0.059 \\
\hline & 1,2 & $24.4 \%$ & $15.2 \%$ & & & & \\
\hline \multirow[t]{2}{*}{ GCS } & $<13$ & $41.9 \%$ & $54.5 \%$ & 0.115 & 1.171 & $0.603-2.276$ & 0.641 \\
\hline & 14,15 & $58.1 \%$ & $45.5 \%$ & & & & \\
\hline
\end{tabular}

RIA: ruptured intracranial aneurysm, M: male, F: female, IC: internal carotid artery, AC: anterior cerebral artery, MC: middle cerebral artery, P: posterior cerebral artery, ICH: intracerebral hemorrhage, IVH: intraventricular hemorrhage, VS: vasospasm, mRS: modified Rankin Scale, mFisher: modified Fisher, GCS: Glasgow Coma Scale

0.021), $\mathrm{MC}$ で他の部位より有意に多かった $(\mathrm{p}=0.045)$. 多変量解析では，男性であることが $6 \mathrm{~mm}$ 以上の破裂脳動 脈瘤に関係する唯一の独立因子であった $(60.8 \%$ vs $48.6 \%$ ： OR 1.954 ; 95\% CI 1.04-3.671).

\section{考察}

破裂細動脈瘤の平均最大径を比較すると, 男性, 中大脳 動脈, 脳内出血あり, 予後不良群 $(\mathrm{mRS}=3-6)$ で有意差を 認め, 動脈瘤サイズは予後に影響する可能性が示唆され た。この結果より，予後良好群 $(\mathrm{mRS}=0-2)$ と予後不良群 $(\mathrm{mRS}=3-6)$ に分け予後不良因子を検討した結果， $6 \mathrm{~mm}$ 以上の破裂脳動脈㢚は独立した予後不良因子であった，破 裂脳動脈瘤のサイズと予後について，本邦の報告では，島 根県出雲市の症例集積で $5 \mathrm{~mm}$ 以上の破裂脳動脈瘤は再出 血や脳血管攣縮，水頭症の合併が有意に多く，独立した予 後不良因子 ${ }^{7)}$ とされている．破裂脳動脈瘤の大きさが予後 悪化のリスクとなる機序については未解明な部分が多い が，破裂脳動脈瘤の大きさが再出血のリスクと相関してお り予後不良となりやすいとの報告があり ${ }^{814)}$ ，今後検証し ていく余地がある．今回のわれわれの報告では再出血の有 無との相関は評価していなかったため，今後の課題とした い。また，手術手技による合併症は脳動脈瘤の大きさと相
関はしないと報告される2)一方で, giant aneurysm は術中 破裂や，手術操作による脳梗塞・脳挫傷などの頻度が高い と報告されているが年, 今回のわれわれの検討では動脈瘤 のサイズによって，これら術中破裂や，手術操作による脳 梗塞・脳挫傷などの頻度に違いを認めなかった。これ は，われわれのシリーズでは giant aneurysm は 2 例のみ と少なかったことが影響していると考えられた。

また，副検討項目である最大径 $6 \mathrm{~mm}$ 以上の症例の臨床 的特徵としては, 男性であることのみが $6 \mathrm{~mm}$ 以上の独立 因子であった，主要血管全体の破裂脳動脈瘤サイズと性別 の相関を解析した報告はないが，前交通動脈の破裂脳動脈 瘤に関して, 最大径は男性のほうが女性に比較して大きい が性別は予後とは関連しないとの報告 ${ }^{10)}$ がある。一方で, 哭煙が前交通動脈脳動脈瘤のサイズ増大の独立因子である という報告 ${ }^{15}$ もあり，男性の契煙量が女性と比較して多い ことが，男性で動脈瘤が大きくなる原因と推測できる。さ らに, 喫煙者の未破裂脳動脈瘤は非契煙者と比較し娘脳動 脈瘤を伴っている率が有意に高いという報告 ${ }^{12)}$ や，娘脳動 脈瘤を有する未破裂脳動脈瘤は破裂リスクが有意に高いと いう報告 ${ }^{11)}$ 考慮すると, 男性は女性と比較して契煙量が 多いため娘脳動脈瘤を形成しやすい分, 破裂脳動脈瘤の最 大径が大きくなると考察できる。 


\section{結＼cjkstart語}

最大径が $6 \mathrm{~mm}$ 以上の破裂脳動脈瘤は独立した予後不良 因子であった。また， $6 \mathrm{~mm}$ 以上の破裂脳動脈瘤は男性に 多かった，破裂脳動脈瘤の大きさが予後を左右する機序に ついては，今後の症例の蓄積とさらなる検討が必要と考え られる。

本論文の要旨は, 第 46 回日本脳卒中の外科学会 $(2017$ 年 3 月：大阪)において発表した.

著者全員は日本脳神経外科学会への COI 自己申告を完 了しています，本論文の発表に関して開示すべきCOI は ありません。

\section{文献}

1) Boogaarts $\mathrm{HD}$, van Lieshout $\mathrm{JH}$, van Amerongen $\mathrm{MJ}$, et al: Aneurysm diameter as a risk factor for pretreatment rebleeding: a meta-analysis. J Neurosurg 122: 921-928, 2015

2) Chee LC, Siregar JA, Ghani ARI, et al: The Factors Associated with Outcomes in Surgically Managed Ruptured Cerebral Aneurysm. Malays J Med Sci 25: 32-41, 2018

3) Fisher CM, Kistler JP, Davis JM: Relation of cerebral vasospasm to subarachnoid hemorrhage visualized by computerized tomographic scanning. Neurosurgery 6: 1-9, 1980

4) 藤井 聡, 中山 敏, 鈴木範行, ほか : Large aneurysmに 対する治療. 脳卒中の外科 26: 32-37, 1998

5) Greving JP, Wermer MJ, Brown RD Jr, et al: Development of the PHASES score for prediction of risk of rupture of intracranial aneurysms: a pooled analysis of six prospective cohort studies. Lancet Neurol 13: 59-66, 2014
6) Ho AL, Lin N, Frerichs KU, et al: Smoking and intracranial aneurysm morphology. Neurosurgery 77: 59-66, 2015

7) Inagawa T: Size of ruptured intracranial saccular aneurysms in patients in Izumo City, Japan. World Neurosurg 73: 84-92, 2010

8) International Study of Unruptured Intracranial Aneurysms Investigators: Unruptured intracranial aneurysms-risk of rupture and risks of surgical intervention. N Engl J Med 339: 1725-1733, 1998

9) Korja M, Kivisaari R, Rezai Jahromi B, et al: Size and location of ruptured intracranial aneurysms: consecutive series of 1993 hospital-admitted patients. J Neurosurg 127: 748-753, 2017

10) Lin B, Chen W, Ruan L, et al: Sex differences in aneurysm morphologies and clinical outcomes in ruptured anterior communicating artery aneurysms: a retrospective study. BMJ Open 6: e009920, 2016

11) Lindgren AE, Koivisto T, Björkman J, et al: Irregular Shape of Intracranial Aneurysm Indicates Rupture Risk Irrespective of Size in a Population-Based Cohort. Stroke 47: 12191226, 2016

12) UCAS Japan Investigators, Morita A, Kirino T, et al: The Natural Course of Unruptured Cerebral Aneurysms in a Japanese Cohort. N Engl J Med 366: 2474-2482, 2012

13) Wiebers DO, Whisnant JP, Huston J 3rd, et al: Unruptured intracranial aneurysms: natural history, clinical outcome, and risks of surgical and endovascular treatment. Lancet 362: 103-110, 2003

14) Wu TC, Tsui YK, Chen TY, et al: Rebleeding of aneurysmal subarachnoid hemorrhage in computed tomography angiography: risk factor, rebleeding pattern, and outcome analysis. J Comput Assist Tomogr 36: 103-108, 2012

15) Xia N, Liu Y, Zhong M, et al: Smoking Associated with Increased Aneurysm Size in Patients with Anterior Communicating Artery Aneurysms. World Neurosurg 87: 155-161, 2016 